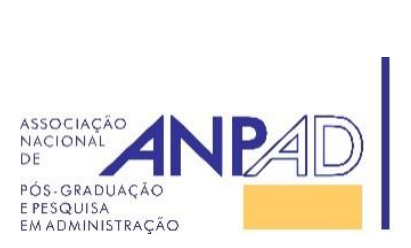

Disponível em

http://www.anpad.org.br/rac

RAC, Rio de Janeiro, v. 20, n. 4, art. 3, pp. 434-457, Jul./Ago. 2016

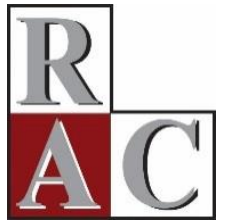

(c) $\mathbf{E Y}$

\title{
Conhecimento Científico sobre Liderança: Uma Análise Bibliométrica do Acervo do The Leadership Quarterly
}

Scientific Knowledge on Leadership: A Bibliometric Analysis of The Leadership Quarterly's Collection

Lucas Martins Turano ${ }^{1}$

Flávia Cavazotte ${ }^{1}$

Pontifícia Universidade Católica do Rio de Janeiro ${ }^{1}$

Artigo recebido em 31.10.2014. Última versão recebida em 03.08.2015. Aprovado em 24.08.2015. Publicado online em 11.03.2016. 


\title{
Resumo
}

Este trabalho investiga a produção científica contemporânea sobre a liderança publicada no The Leadership Quarterly (LQ), o principal periódico internacional dedicado exclusivamente ao tema. O estudo se baseia na aplicação do método bibliométrico aos 368 artigos publicados pela revista nos últimos seis anos, e examina sua autoria, origem e orientação teórica, bem como suas citações e cocitações. O resultado da análise indica que as Novas Teorias sobre a Liderança (Liderança Carismática, Transacional e Transformacional) e a Teoria das Trocas Líder-Seguidor (LMX) são os corpos teóricos dominantes no periódico. Esses trabalhos se orientam, majoritariamente, pela abordagem positivista e aplicam metodologias quantitativas de pesquisa. Essas observações são discutidas quanto às suas implicações para a difusão da produção científica sobre a liderança no contexto nacional e internacional.

Palavras-chave: liderança; análise bibliométrica; citações; cocitações.

\begin{abstract}
This work investigates the contemporary scientific literature on leadership published in The Leadership Quarterly (LQ), the leading international journal devoted exclusively to the subject. The study is based on the application of the bibliometric method to 368 articles published by the journal in the last six years, and examines their authorship, origin, and theoretical orientation, as well as their citations and co-citations. The analysis indicates that the New Leadership Theories (Charismatic, Transactional and Transformational Leadership) and the Leader-Member Exchange Theory (LMX) are the dominant theoretical approaches in the journal. These articles are largely guided by a positivist stance on the subject and apply quantitative research methodologies. These observations are discussed as to their implications for the dissemination of the scientific literature on leadership in the national and international contexts.
\end{abstract}

Key words: leadership; bibliometric study; citations; cocitations. 


\section{Introdução}

Segundo Day e Antonakis (2012), dar sentido às pesquisas sobre liderança pode ser uma tarefa intimidadora, tamanha a profusão de trabalhos publicados sobre o assunto. Como este tem sido um campo fértil e amplo de produção científica, acompanhar as pesquisas da área é uma tarefa complexa até mesmo para pesquisadores experientes. Com o objetivo de sintetizar e analisar algumas tendências gerais no campo, diversos autores têm apresentado revisões narrativas da literatura sobre o tema no cenário nacional e internacional (e.g.: Dinh et al., 2014; Fonseca, Porto, \& Borges-Andrade, 2015). Muitas dessas análises se baseiam em conjuntos específicos de periódicos, que certamente são parte de um universo mais amplo de produção de saber no campo da liderança. Por outro lado, a aplicação de ferramentas bibliométricas de análise à produção científica sobre o tema é mais rara, e poucos são os trabalhos que as utilizam para analisar tendências editoriais específicas (e.g.: Antonakis, Bastardoz, \& Schriesheim, 2014; Fernandes \& Vaz, 2010).

Com base nessas observações, este artigo tem como propósito central investigar a pesquisa científica sobre a liderança publicada no The Leadership Quarterly (LQ) de 2008 a 2013. O LQ é um periódico multidisciplinar, com edições regulares há 25 anos, e que tem a liderança como tema de interesse focal. Com base no seu fator de impacto, que é calculado em função do número de citações feitas referentes aos artigos nele publicados, pode-se dizer que o LQ é a principal referência de produção científica sobre a liderança entre as revistas temáticas existentes. No período analisado neste trabalho, 368 artigos foram publicados pelo jornal. A análise do acervo em questão se concentra na identificação dos corpos teóricos dominantes sobre o tema na revista, na identificação do contexto de origem e perfil dos autores desses trabalhos, e na orientação metodológica das pesquisas encontradas no periódico.

Até a metade da última década, poucos estudos bibliométricos haviam sido publicados no Brasil, sobretudo nas áreas de gestão de pessoas, recursos humanos, relações de trabalho e temas afins (Vieira $\&$ Fischer, 2005). No entanto, este tipo de metodologia oferece uma importante contribuição para a academia, em função de seu caráter norteador como ferramenta para a consolidação da pesquisa sobre temas específicos, na identificação de tendências editoriais e fatores que promovem citações, e de lacunas para pesquisas futuras, e tem sido cada vez mais utilizada na literatura em administração (e.g. Serra, Ferreira, Almeida, \& Vanz, 2012; Sobral \& Mansur, 2013).

Este artigo busca contribuir para a reflexão sobre a liderança enquanto tema de interesse central nas organizações contemporâneas e identificar as bases do conhecimento que têm orientado a produção do principal periódico internacional dedicado ao tema, com base na aplicação do método bibliométrico. Uma vez que a pesquisa científica sobre a liderança tem sido construída majoritariamente no contexto internacional, com relativamente pouca participação de pesquisadores brasileiros nesse contexto (Sant'anna, Vaz, Nelson, Campos, \& Leonel, 2009), este trabalho também contribui para uma melhor compreensão das tendências editoriais da área e para o debate sobre o estado da arte desse campo nos dias atuais.

\section{Referencial Teórico}

A liderança é um dos fenômenos mais estudados nas Ciências Sociais, e constitui temática que já acumula mais de um século de pesquisas científicas (Day \& Antonakis, 2012). Como ela está presente em inúmeros ambientes, tais como escolas, quartéis, empresas, comunidades e quaisquer outras organizações ou grupos sociais, a liderança é um tópico de interesse multidisciplinar e um rico campo para estudos e pesquisas (Bass, 2008). Estudar a liderança viabiliza um melhor entendimento das dinâmicas sociais e das realizações coletivas. Particularmente nas áreas de Gestão e Administração de Negócios, a liderança é considerada um fenômeno de interesse central, veículo fundamental na criação de valor nas empresas (Schein, 2007), no desenho e na execução eficaz de estratégias nas organizações 
(Kotter, 2001), e por isso tem recebido destaque tanto na literatura acadêmica (Yukl, 1989, 2012) quanto na mídia de negócios (e.g.: Schreyer, 2010).

De acordo com Burns (1978), até o final da década de 1970, muitas informações haviam sido levantadas sobre a liderança, e mais de 130 diferentes definições apresentadas, sem que houvesse emergido nenhuma conceituação definitiva ou plenamente aceita. De fato, a liderança é um fenômeno complexo e multifacetado (Day \& Antonakis, 2012), o que dificulta a sua precisa definição. Contudo, as diferentes acepções disponíveis parecem explorar aspectos distintos desse processo, enfatizando um ou outro fator específico (Yukl, 2006). Com base no conhecimento acumulado sobre o tema, é possível dizer que há alguns elementos essenciais que caracterizam a liderança e sobre os quais existe consenso. A liderança envolve: (a) um processo de influência, (b) a interação dinâmica entre líderes e seguidores, (c) a busca pelo atingimento de metas ou objetivos específicos, e (d) a promoção de algum grau de transformação em um determinado contexto social. Assim, a liderança pode ser definida como um processo interativo no qual líderes influenciam seus seguidores para empreender esforços e alcançar objetivos transformadores dos contextos em que atuam.

Delfino, Silva e Rohde (2010) analisaram a produção de pesquisas sobre liderança no Brasil de 1995 a 2009 e observaram um aumento nas publicações sobre o tema com o passar dos anos, particularmente entre 2006 e 2009. Por outro lado, evidenciou-se, também, que muitos dos estudos apresentados em eventos não evoluíram para uma publicação em periódicos. Mais recentemente, com base em um levantamento dos artigos publicados sobre liderança em periódicos nacionais de 1996 a 2013, Fonseca, Porto e Borges-Andrade (2015) descrevem o campo no Brasil como ainda embrionário, onde predominam estudos qualitativos exploratórios.

\section{Histórico das pesquisas sobre liderança}

O campo de estudos sobre a liderança perpassa de forma ampla diferentes disciplinas (ver Bryman, Collinson, Grint, Jackson, \& Uhl-Bien, 2011). As perspectivas políticas e filosóficas se estendem desde os clássicos da antiguidade até as abordagens críticas da pós-modernidade, e examinam aspectos do fenômeno associados às dinâmicas de poder e à ética. As perspectivas econômicas e sociológicas, em associação com as teorias organizacionais e o pensamento administrativo, analisam a liderança com foco em temas como estratégia, redes e cultura. Na perspectiva da psicologia, disciplina que talvez tenha mais contribuído para a formação das teorias contemporâneas sobre liderança, o fenômeno tem sido estudado a partir de conceitos como personalidade e diferenças individuais, interações sociais e do comportamento em grupo.

Das abordagens clássicas, que remontam à antiguidade, focadas nas figuras de emblemáticos conquistadores e líderes militares, aos dias atuais, as visões sobre a liderança em larga escala refletem o contexto histórico, político e cultural no qual emergiram (Grint, 2011) - é sobre o cenário em que a liderança ocorre, seu contexto temporal e seus desafios, que discorrem as teorias. Apesar de a literatura demarcar o começo das pesquisas científicas sobre o tema no início do século XX (Day \& Antonakis, 2012; Lowe \& Gardner, 2001), vários textos produzidos na era antiga e medieval continuam populares na atualidade, como A Arte da Guerra, o primeiro e talvez mais notório manual sobre liderança, elaborado com base nos ensinamentos de Sun Tzu entre 400-320 a.C., e o livro O Príncipe, escrito entre 1513 e 1514, em que Machiavel descreve as práticas políticas de seu tempo.

De acordo com Grint (2011), ainda na era vitoriana, o fascínio pela figura do herói inicia a busca pelo entendimento das características definidoras de um líder. Até o final da década de 1940, a escola dos traços, também denominada teoria do grande homem, considerada a primeira escola entre as perspectivas formais sobre o tema, teve um papel dominante nos estudos sobre o fenômeno (House \& Aditya, 1997; Northouse, 2010). Partindo do pressuposto de que líderes já nasciam predestinados e equipados para exercer esse papel, essa perspectiva buscou identificar os traços e as qualidades inatas que fazem com que determinada pessoa se torne um grande líder (Day \& Antonakis, 2012). Essa teoria foi criticada por ser vista como determinista, ignorar fatores situacionais e não tratar o processo da 
liderança de uma maneira holística (Northouse, 2010). Segundo Gardner, Lowe, Moss, Mahoney e Cogliser (2010), houve um declínio na proporção de artigos publicados com foco nessa perspectiva.

Orientado pela expansão da indústria, pelo surgimento das grandes corporações e pela atenção aos sistemas e processos racionais na administração, posteriormente o pensamento sobre a liderança se afasta da figura do líder como herói para equalizá-la com a ocupação eficaz de posições de gestão (Grint, 2011). Assim, na década de 1950, muitos pesquisadores passaram a atentar para a forma como os líderes agem no ambiente de trabalho, através das abordagens comportamentais (Yukl, 2006). Apesar de também ter como foco central a figura do líder, nesta perspectiva o comportamento grupal passou a ser analisado (Bryman, 2004). Nesse sentido, foi verificado que os líderes variavam na orientação de seus comportamentos. Líderes orientados para pessoas buscariam fundamentalmente criar um forte relacionamento com seus subordinados. Por outro lado, o foco do líder orientado para tarefas seria a produtividade e o cumprimento de metas laborais (Parry \& Bryman, 2006). Apesar de o interesse por essa perspectiva ter diminuído na atualidade (Day \& Antonakis, 2012), muitas de suas ideias originais foram incorporadas em perspectivas posteriores sobre a liderança.

No período que se estendeu até o final da década de 1960, em meio à Guerra Fria e expansão da dominação americana no cenário global, o entendimento racional sobre o contexto e a necessidade de adaptação passam a ter precedência no pensamento sobre a liderança (Grint, 2011). Assim, surgiram as teorias contingenciais. Segundo Yukl (2006), essa escola explora certos aspectos do contexto em que a liderança ocorre, e que podem alterar a efetividade e o poder de influência dos líderes. Para exercer influência efetivamente sobre um grupo, o líder deveria ser capaz de adaptar seu comportamento às diferentes situações (Bowditch \& Buono, 2002). Alguns dos aspectos situacionais relevantes seriam a natureza da tarefa a ser realizada, o grau de legitimidade e poder do líder estabelecido por via de estruturas formais, e o tipo de relacionamento entre ele e os membros do grupo (Fiedler, 1967). No entanto, uma forte crítica a essa perspectiva é o fato de ela não ter sido verificada empiricamente através de métodos robustos de investigação científica, e se basear em construtos que não foram adequadamente validados e testados (Yukl, 2006). Gardner et al. (2010) afirmam que essas perspectivas também se tornaram praticamente inativas no campo de estudos sobre a liderança, constituindo apenas $1 \%$ dos trabalhos publicados na primeira década do século XXI.

Na década de 1970, logo após o movimento das teorias contingenciais, surgiu a escola relacional da liderança. Apesar de a discussão sobre a orientação para relacionamentos estar presente na perspectiva comportamental, e das perspectivas contingenciais considerarem o tipo de relação existente entre líderes e seguidores, as teorias até então haviam estudado o fenômeno com foco no líder ou no contexto. Essa escola, porém, toma a relação entre o líder e cada um de seus seguidores como objeto central de interesse. O movimento começa com a Teoria dos Vínculos Diádicos Verticais (Dansereau, Graen, \& Haga, 1975) e evolui até o desenvolvimento da teoria das Trocas entre Líder e Seguidores, conhecida pela sigla LMX (Leader-Member Exchange) (Graen \& Uhl-bien, 1995).

De acordo com Graen e Uhl-bien (1995), relacionamentos diádicos verticais entre um líder e seus diversos seguidores poderiam variar em termos qualitativos, desde uma troca limitada ao contrato formal de trabalho, na qual o indivíduo tem seus papéis estreitamente definidos, até um relacionamento de alta qualidade, baseado na confiança, no respeito e no alto envolvimento, e no qual os indivíduos detêm papéis expandidos. Esses dois tipos de relacionamentos permitiriam a formação de um grupo de seguidores mais próximos do líder e outro mais distante, denominados in-group e out-group, respectivamente (Graen \& Uhl-bien, 1995). Relacionamentos de alta qualidade entre um líder e seus seguidores promovem melhores resultados do que aqueles em que o respeito mútuo e a confiança estão ausentes, achados esses que foram confirmados em diversas pesquisas empíricas (Gerstner \& Day, 1997). No entanto, algumas ideias básicas dessa teoria não foram totalmente desenvolvidas, como a explicação sobre que fatores facilitariam o desenvolvimento de uma relação de alta qualidade entre líder e seguidores (Northouse, 2010).

Nos anos 1970 e 1980, alguns autores passaram também a questionar o pensamento tradicional sobre a liderança, argumentando que o fenômeno estaria muito mais na mente dos seguidores do que nas ações objetivas do líder (e.g.: Lord, Binning, Rush, \& Thomas, 1978). Essas perspectivas têm em 
comum o deslocamento da atenção da figura do líder para a dos seguidores e seu papel no processo da liderança. Como para esses autores são os seguidores que legitimam e empoderam os líderes, sua atenção se debruça sobre suas atribuições (e.g.: Calder, 1977; Meindl, Ehrlich, \& Dukerich, 1985). Alguns pensadores chegam a considerar os líderes irrelevantes, inaugurando o ceticismo como uma escola de pensamento sobre o tema (Pfeffer, 1977). Nesse período, tem origem a abordagem de teorias implícitas da liderança (e.g.: Eden \& Leviatan, 1975), baseada no pressuposto de que expectativas sobre o líder influenciam as percepções dos indivíduos sobre seu comportamento. O foco nos seguidores também propulsiona as teorias focadas no processamento de informações (Lord, Foti, \& De Vader, 1984), que procuram compreender o papel das cognições, afetos, identidade dos seguidores e da prototipicalidade dos líderes no processo da liderança. Outra perspectiva que também desloca a atenção da figura do líder para os seus substitutos discute a liderança dispersa (Manz \& Sims, 1991), que em conjunto com o enfoque gerencial no conceito de empoderamento (e.g.: Conger \& Kanungo, 1988) e em equipes autogerenciadas, contribuem para as bases da teoria da liderança compartilhada (Pearce \& Sims, 2001).

A partir do final da década de 1980, após um período de relativa quietude no campo, surge a teoria da liderança carismática, uma das perspectivas que constituem a escola da nova liderança (Day \& Antonakis, 2012). A teoria, considerada por alguns autores uma volta ao passado por seu enfoque em indivíduos inspiradores (Grint, 2011), causou um grande impacto e desenvolveu as ideias do sociólogo Max Weber (1920/1947), que aplicou originalmente o conceito de carisma aos líderes. Ela se baseia, primeiramente, no estudo de House (1977) e, posteriormente, nos trabalhos de Conger e Kanungo (1987) e Shamir, House e Arthur (1993). De acordo com esses autores, carisma é um fator de influência atribuído pelos seguidores a um líder. Líderes carismáticos têm, geralmente, um vínculo emocional único com seus seguidores, baseado, essencialmente, em valores compartilhados. Dessa forma, o impacto oriundo de suas habilidades carismáticas auxiliaria no estímulo ao engajamento dos seguidores (House, 1977; Shamir, House, \& Arthur, 1993). Além disso, a grande maioria desses líderes teria uma forte autoconfiança e convicção em seus próprios ideais e crenças, assim como uma alta necessidade de poder (Yukl, 2006).

As teorias da liderança transformacional e transacional, que constituem a chamada Full-Range Leadership Theory, ou Modelo de Extensão Total da Liderança (Bass, 2008), também fazem parte da escola da nova liderança, e estão baseadas, primordialmente, no trabalho seminal de Burns (1978). De acordo com esse autor, as relações transformadoras têm um efeito maior nos seguidores e nas massas do que as transacionais, porque estão baseadas no transcender e na busca pelo alcance de metas e ideais de grande impacto, compartilhadas pelo líder e seus seguidores. Por outro lado, as relações transacionais teriam um escopo mais limitado, sendo focadas em interesses de parte a parte, transações que objetivam obter compensações materiais e emocionais ou apoio político (Burns, 1978).

A teoria da liderança transformacional parte das ideias de Burns e das discussões sobre carisma presentes na literatura, mas centraliza a atenção na motivação e desenvolvimento dos seguidores (Northouse, 2010). A perspectiva toma fôlego entre pesquisadores americanos na década de 1990, após a globalização incrementar a competição nos mercados, e a introdução de novas tecnologias e de práticas gerenciais como o redesenho de processos aumentarem a necessidade de gerenciar mudanças no mundo corporativo. Cinco dimensões básicas compõem esse tipo de liderança: (a) carisma, (b) influência idealizada, (c) motivação inspiracional, (d) estimulação intelectual e (e) consideração individualizada (Bass, 1998). Contudo, a dimensão do carisma, baseada, fundamentalmente, na própria liderança carismática, não é considerada um comportamento do líder transformacional por um grande número de autores (e.g.: Yukl, 2006). De acordo com Gardner et al. (2010), as teorias da nova liderança (carismática, transacional e transformacional) dominaram o campo em termos de número de publicações nos anos subsequentes.

Na primeira década do século XXI, em meio a ondas de ataques terroristas, escândalos corporativos, crises econômicas e desafios socioambientais, emergiu uma nova teoria baseada na filosofia e na psicologia positiva: a teoria da liderança autêntica (Yukl, 2006). Ela busca discutir, essencialmente, como seria uma liderança mais ética e mais efetiva para lidar com os desafios de nosso tempo (Luthans \& Avolio, 2003). De acordo com a literatura, os quatro principais comportamentos de líderes autênticos são: (a) processamento balanceado de informações, (b) perspectiva moral 
internalizada, (c) transparência relacional e (d) autoconhecimento (Gardner, Avolio, Luthans, May, \& Walumbwa, 2005).

Uma crítica a essa abordagem é o fato de ela não ser considerada totalmente nova, uma vez que, para alguns autores, ela se confunde com a teoria da liderança ética (Brown, Treviño, \& Harrison, 2005) e a da liderança transformacional, mesmo que parcialmente (e.g.: Cooper, Scandura, \& Schriesheim, 2005). Apesar de já contar com diversos trabalhos publicados (Gardner, Lowe, Moss, Mahoney, \& Cogliser, 2010), esta teoria ainda careceria de um desenvolvimento mais substancial (Yammarino, Dionne, Schriesheim, \& Dansereau, 2008).

A descrição das perspectivas sobre liderança apresentada nesta seção não tem o intuito de ser exaustiva, mas de clarificar como o pensamento sobre o tema vem evoluindo ao longo do tempo. A partir da reflexão sobre as proposições de algumas das principais escolas de pensamento, depreende-se que as teorias sobre liderança têm procurado não apenas esclarecer a natureza do fenômeno, mas, também, identificar fatores associados à sua efetividade. Dessa forma, as escolas enfatizam diferentes aspectos tais como traços e comportamentos dos líderes, fontes de poder e características dos seguidores, bem como dinâmicas relacionais que promovem ou favorecem o exercício do papel de líder, isto é, de agente capaz de influenciar seguidores a perseguir objetivos transformadores dos contextos em que atuam. Tal busca parte do pressuposto de que a liderança pode ser explicada e até mesmo favorecida por esse conhecimento, se aplicado ao desenvolvimento de líderes (Yukl, 2012). Assim, os estudos científicos sobre o tema vêm incrementalmente avançando o conhecimento sobre esse complexo processo, que constitui um importante catalisador das realizações coletivas e de excelência nas organizações.

\section{Método do Estudo}

Este trabalho, exploratório e de natureza quantitativa, busca fazer uma análise da produção científica contemporânea sobre o tema liderança, a partir de uma investigação sistemática do acervo do periódico internacional The Leadership Quarterly (LQ). Com esse objetivo, adotou-se o método bibliométrico como técnica para examinar o universo de artigos publicados na revista no intervalo que compreende janeiro de 2008 até dezembro de 2013, a fim de verificar os principais corpos teóricos que orientam sua produção e as tendências editoriais da revista.

O periódico internacional LQ foi fundado em 1990 e possui publicações quadrimestrais. A revista, que segue o sistema de double-blind peer review, abrange a produção científica multidisciplinar sobre a liderança nos campos da ciência política, psicologia organizacional, sociologia e a ciência comportamental, entre outros, e almeja como audiência pesquisadores, consultores, gestores executivos e administradores de forma geral, assim como educadores que lecionem a cadeira de liderança nas grades universitárias (Elsevier, n.d.).

O periódico foi escolhido como objeto de estudo intencionalmente, uma vez que pode ser considerado uma referência internacional sobre a liderança. Ele figura entre os dez que estão no topo dos rankings internacionais da área de comportamento organizacional e publicam pesquisas sobre liderança, sendo o único temático. Entre os jornais que têm a liderança como foco central, o LQ é presentemente a revista com o maior fator de impacto segundo o JCR (FI $2013=2,01$; FI em 5 anos = 3,01 ). Vale ressaltar, ainda, que o volume de produção do periódico no campo é expressivo: considerando apenas pesquisas originais sobre liderança, de 2000 a 2012 o LQ publicou um total de artigos quatro vezes maior que o do Journal of Applied Psycology, e dez vezes maior que o do Academy of Management Journal (Dinh et al., 2014). Quanto ao intervalo temporal do estudo, buscou-se coletar os artigos dos últimos seis anos, uma vez que podem ser classificados como recentes e, por isso, representam as pesquisas de ponta sobre o tema veiculadas pelo jornal. 
A bibliometria é um método de análise de dados bibliográficos que tem o intuito de encontrar padrões e tendências por intermédio do tratamento de citações e cocitações (D. White \& Mccain, 1998; H. White \& Griffith, 1981). Esse método pode ter como objeto central uma ampla gama de trabalhos, como teses e dissertações, autores, livros, notícias, entre outros (Serra et al., 2012). Essencialmente, a análise de citações procura identificar os estudos referendados nos trabalhos publicados. Quando um autor busca uma referência e realiza uma citação, parte-se do princípio de que os trabalhos citados são afins e, na maior parte dos casos, relevantes para o embasamento teórico e a trama argumentativa da pesquisa realizada (Serra et al., 2012). Portanto, depreende-se que, essencialmente, os trabalhos que recebem mais citações apresentam uma maior influência no desenvolvimento de uma teoria, na discussão sobre um fenômeno ou em um campo do conhecimento (Antonakis et al., 2014).

A etapa subsequente da análise de cocitações se assenta em identificar possíveis pares ou grupos de trabalhos que são citados simultaneamente em outros. Esse tipo de análise busca mapear trabalhos com conteúdos comuns e teorias semelhantes em estudo. A partir da construção conjunta de uma teoria ou campo do conhecimento, por meio de pares ou grupos de trabalhos, as ideias propostas revelam sua forte relevância e alcance (Serra et al., 2012). D. White e McCain (1998) afirmam ainda que, a partir disso, é possível identificar de que forma os trabalhos estão relacionados.

\section{Procedimentos e amostra}

No que concerne aos procedimentos da pesquisa, realizou-se, primeiramente, uma busca na base de dados do ISI Web of Knowledge. Essa ferramenta foi escolhida porque ela realiza a indexação em sua base de todos os artigos publicados no LQ no período selecionado para a realização do estudo. $\mathrm{O}$ próximo passo foi a utilização do software Bibexcel, que organizou os dados necessários para a construção das tabelas descritivas de análise. As referências foram normalizadas manualmente, a fim de que os nomes de autores, assim como os volumes e páginas publicadas, não apresentassem quaisquer inconsistências. Quando livros iguais, porém de edições diferentes, foram citados, eles foram agrupados de acordo com a edição que havia recebido mais citações. Na penúltima fase, a matriz de cocitações gerada no Bibexcel foi inserida no software Ucinet, gerando uma rede de cocitações. Da mesma forma, como última etapa, a matriz de cocitações foi também inserida no Statistics Packet for Social Science (SPSS) para uma análise multivariada, que culminou na construção de um mapa de cocitações com seus clusters identificados a partir da leitura detalhada dos trabalhos.

A Figura 1 ilustra e resume o método utilizado, indicando cada uma das etapas realizadas ao longo do processo de pesquisa.

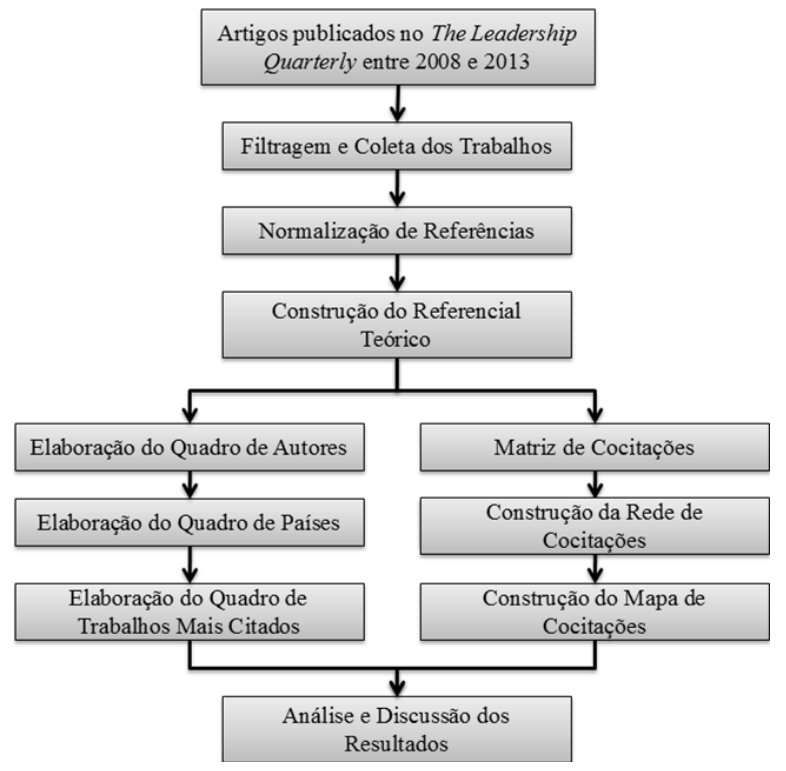

Figura 1. Diagrama de Tratamento dos Dados Fonte: Elaborado pelos Autores. 
Seguindo os procedimentos descritos, a pesquisa identificou 368 artigos que foram obtidos para a aplicação dos procedimentos estabelecidos na metodologia. Não foram incluídos na amostra artigos que constituíam editoriais introdutórios às diversas edições do periódico, tipicamente de autoria do corpo editorial da revista. Todos os artigos incluídos passaram pelo processo de double-blind peer review.

\section{Análise dos Resultados}

Primeiramente, buscou-se verificar a frequência de publicações por autor. Observou-se que os 368 artigos publicados no período tiveram 749 autores diferentes, sendo, no total, 1074 autores, o que dá uma média geral de cerca de três autores por artigo $(=2,92)$. Além disso, dentre os 749 diferentes autores, 593 publicaram somente um artigo no período (79,2\%). Os autores que mais publicaram artigos no LQ no intervalo considerado estão listados na Tabela 1. A ordem de autoria no artigo publicado não foi considerada, sendo contabilizados todos os trabalhos em que os autores foram listados como coautores. Os dez autores que mais publicaram no periódico tiveram entre 6 e 14 trabalhos aceitos, sendo o pesquisador Michael Mumford o primeiro do ranking, com uma média de dois artigos por ano. Cabe notar que, atualmente, nove desses dez autores que mais publicaram no período são membros do corpo editorial do próprio jornal, e apenas Stephanie Johnson não faz parte desse grupo (Elsevier, n.d.).

Tabela 1

Autores que Mais Publicaram no The Leadership Quarterly no Período

\begin{tabular}{clccclcc}
\hline Rank & Autores & Publ & \% & Rank & Autores & Publ. & \% \\
\hline $1^{\text {o }}$ & Mumford, Michael D. & 14 & 3,8 & $6^{\text {o }}$ & Hunter, Samuel T. & 8 & 2,2 \\
$2^{\text {o }}$ & Yammarino, Francis J. & 13 & 3,5 & $7^{\text {o }}$ & Johnson, Stefanie K. & 7 & 1,9 \\
$3^{\text {o }}$ & Avolio, Bruce J. & 12 & 3,3 & $8^{\text {o }}$ & Walumbwa, Fred O. & 7 & 1,9 \\
$4^{\text {o }}$ & Van Knippenberg, Dann & 9 & 2,4 & $9^{\text {o }}$ & Hannah, Sean T. & 6 & 1,6 \\
$5^{\text {o }}$ & Schriesheim, Chester A. & 9 & 2,4 & $10^{\circ}$ & Lord, Robert G. & 6 & 1,6 \\
\hline
\end{tabular}

Nota. Fonte: Elaborado pelos autores.

A segunda fase da análise buscou captar a nacionalidade da instituição de afiliação do autor principal dos 368 trabalhos identificados. Evidenciou-se que, em mais da metade dos trabalhos $(213=$ $57,9 \%$ ), o autor principal pertence ao quadro docente de universidades americanas. Essa observação reforça a ideia de que a pesquisa veiculada pelo periódico ainda se concentra majoritariamente no eixo EUA-EU (ver Tabela 2), com menor representação de pesquisadores de outros continentes, até mesmo por via de eventuais estudos de validação de teorias da liderança. Dessa forma, pode-se dizer que as pesquisas publicadas nos últimos anos no LQ ainda estão baseadas predominantemente no pensamento de pesquisadores imersos no contexto americano e europeu, que permanecem sendo os principais polos de pesquisa difundida na comunidade acadêmica internacional neste campo no periódico. 
Tabela 2

Países de Filiação dos Autores Principais

\begin{tabular}{clccclcc}
\hline Rank & País do Autor Principal & Qtd. & \% & Rank & País do Autor Principal & Qtd. & \% \\
\hline $1^{\circ}$ & Estados Unidos & 213 & 57,9 & $14^{\circ}$ & Coreia do Sul & 3 & 0,8 \\
$2^{\text {o }}$ & Holanda & 27 & 7,3 & $15^{\circ}$ & Taiwan & 3 & 0,8 \\
$3^{\text {o }}$ & Inglaterra & 21 & 5,7 & $16^{\circ}$ & Dinamarca & 2 & 0,5 \\
$4^{\text {o }}$ & Austrália & 15 & 4,1 & $17^{\circ}$ & Grécia & 2 & 0,5 \\
$5^{\circ}$ & Canadá & 14 & 3,8 & $18^{\circ}$ & Itália & 2 & 0,5 \\
$6^{\circ}$ & China & 14 & 3,8 & $19^{\circ}$ & Malásia & 2 & 0,5 \\
$7^{\circ}$ & Alemanha & 12 & 3,3 & $20^{\circ}$ & Suécia & 2 & 0,5 \\
$8^{\circ}$ & Israel & 10 & 2,7 & $21^{\circ}$ & Suíça & 2 & 0,5 \\
$9^{\circ}$ & Nova Zelândia & 5 & 1,4 & $22^{\circ}$ & Brasil & 1 & 0,3 \\
$10^{\circ}$ & Noruega & 5 & 1,4 & $23^{\circ}$ & Espanha & 1 & 0,3 \\
$11^{\circ}$ & Singapura & 4 & 1,1 & $24^{\circ}$ & Finlândia & 1 & 0,3 \\
$12^{\circ}$ & Bélgica & 3 & 0,8 & $25^{\circ}$ & País de Gales & 1 & 0,3 \\
$13^{\circ}$ & Portugal & 3 & 0,8 & - & Total & 368 & 100 \\
\hline
\end{tabular}

Nota. Fonte: Elaborado pelos autores.

Vale ressaltar que em 1997, 98\% da produção científica sobre liderança era oriunda dos Estados Unidos (House \& Aditya, 1997). A julgar pela produção recente publicada no LQ, a participação de autores de outras nações aumentou de 2 para 42\%, o que representaria, assim, uma tendência à internacionalização na revista. Além disso, de acordo com a investigação realizada, somente um trabalho teve como autor principal um pesquisador do Brasil. Nesse sentido, os resultados confirmam aquilo que foi exposto por Delfino et al. (2010): que pesquisadores brasileiros ainda têm poucas publicações e visibilidade nesse campo de pesquisa no cenário internacional, a julgar pela produção difundida pelo LQ.

Na terceira etapa da análise, foi verificado que referências foram mais citadas entre os 368 artigos publicados no The Leadership Quarterly no período (Tabela 3). Optou-se, intencionalmente, por tabelar somente publicações que foram citadas 25 vezes ou mais, ou seja, em no mínimo $5 \%$ dos artigos publicados no período. Seguindo essa restrição, chegou-se ao total de 54 publicações, que foram listadas por ordem decrescente de frequência de citações. O livro de Gary Yukl (2006) - Leadership in Organizations - foi o que obteve o maior número de citações (111). Ou seja, 30,2\% dos artigos publicados no LQ nos últimos seis anos citaram essa referência. 
Tabela 3

Os 54 Trabalhos Mais Citados de Janeiro de 2008 a Dezembro de 2013 no The Leadership Quarterly

\begin{tabular}{|c|c|c|c|}
\hline Rank & Trabalhos & Qtd & $\%$ \\
\hline $1^{\circ}$ & Yukl, G. (2006). Leadership in Organizations & 111 & 30,2 \\
\hline $2^{\circ}$ & Bass, B. M. (1990). Bass \& Stogdill's Handbook Leadership & 104 & 28,3 \\
\hline $3^{\circ}$ & Bass, B. M. (1985). Leadership \& Perform Beyond Expect & 102 & 27,7 \\
\hline $4^{\mathrm{o}}$ & Graen, G. B., \& Uhl-Bien, M. (1995). Leadership Quarterly & 82 & 22,3 \\
\hline $5^{\circ}$ & $\begin{array}{l}\text { Podsakoff, P. M., Mackenzie, S. C., Podsakoff, N. P., \& Lee, J. (2003). Journal of } \\
\text { Applied Psy. }\end{array}$ & 81 & 22,0 \\
\hline $6^{\circ}$ & Shamir, B. et al. (1993). Organization Science & 76 & 20,7 \\
\hline $7^{\circ}$ & Conger, J.A., \& Kanungo R. N. (1998). Charismatic Leadership & 62 & 16,8 \\
\hline $8^{\circ}$ & Judge, T. A., \& Piccolo, R.F. (2004). Journal of Applied Psy. & 61 & 16,6 \\
\hline $9^{\circ}$ & Aiken, L. S., \& West, S. G. (1991). Multiple Regression & 61 & 16,6 \\
\hline $10^{\circ}$ & Bass, B. M. (1998). Transformational Leadership: Industry & 60 & 16,3 \\
\hline $11^{\circ}$ & Burns, J. M. (1978). Leadership & 54 & 14,7 \\
\hline $12^{\circ}$ & Lowe, K. B. et al. (1996). Leadership Quarterly & 54 & 14,7 \\
\hline $13^{\circ}$ & Bliese, P. D. (2000). Within-Group Agreement & 49 & 13,3 \\
\hline $14^{\circ}$ & Bass, B. M., \& Avolio B. J. (2004). Multifactor Leadership & 49 & 13,3 \\
\hline $15^{\circ}$ & Gerstner, C. R., \& Day, D. V. (1997). Journal of Applied Psy. & 49 & 13,3 \\
\hline $16^{\circ}$ & Judge, T. A., Bono, J. E., Ilies, R., \& Gerhardt, M. (2002). Journal of Applied Psy. & 46 & 12,5 \\
\hline $17^{\circ}$ & $\begin{array}{l}\text { Yammarino, F. J., Dionne, S. D., Chun, J. A., \& Dansereau, F. (2005). Leadership } \\
\text { Quarterly }\end{array}$ & 46 & 12,5 \\
\hline $18^{\circ}$ & Baron, R. M., \& Kenny D. A. (1986). J. Pers. \& Social Psychol. & 44 & 12,0 \\
\hline $19^{\circ}$ & Lord, R. G., \& Maher, K. J. (1991). Leadership \& Information & 41 & 11,1 \\
\hline $20^{\circ}$ & Conger, J. A., \& Kanungo R. N. (1987). Acad. of Manag. Rev. & 39 & 10,6 \\
\hline $21^{\circ}$ & $\begin{array}{l}\text { Podsakoff, P. M., Mackenzie, S. B., Moorman, R. H., \& Fetter, R. (1990). Leadership } \\
\text { Quarterly }\end{array}$ & 39 & 10,6 \\
\hline $22^{\circ}$ & Mumford, M. D. (2006). Pathways Outstanding Leadership & 37 & 10,1 \\
\hline $23^{\circ}$ & James, L. R., Demaree, R. G., \& Wolf, G. (1984). Journal of Applied Psy. & 37 & 10,1 \\
\hline $24^{\circ}$ & Bono, J. E., \& Illies, R. (2006). Leadership Quarterly & 34 & 9,2 \\
\hline $25^{\circ}$ & House, R. J. \& Aditya, R.N. (1997). Journal of Management & 34 & 9,2 \\
\hline $26^{\circ}$ & Avolio, B. J., \& Gardner, W. L. (2005). Leadership Quarterly & 33 & 9,0 \\
\hline $27^{\circ}$ & Bono, J. E., \& Judge, T. A. (2004). Journal of Applied Psy. & 33 & 9,0 \\
\hline $28^{\circ}$ & $\begin{array}{l}\text { House, R. J., Hanges, P. J., Javidan, M., Dorfmann, P. W., \& Gupta, V. (2004). } \\
\text { Culture, Leadership, and Organ. }\end{array}$ & 33 & 9,0 \\
\hline $29^{\circ}$ & Lord, R. G., Foti, R. J., \& De Vader, C. L. (1984). Organ. Behavior\& Human Perf. & 33 & 9,0 \\
\hline $30^{\circ}$ & Dansereau, F., Alutto, J. A., \& Yammarino, F. J. (1984). Theory Testing in Org. Behav. & 32 & 8,7 \\
\hline
\end{tabular}




\section{Tabela 3 (continuação)}

\begin{tabular}{|c|c|c|c|}
\hline Rank & Trabalhos & Qtd & $\%$ \\
\hline $31^{\circ}$ & Bass, B. M., \& Steidlmeier, P. (1999). Leadership Quarterly & 31 & 8,4 \\
\hline $32^{\circ}$ & Yukl, G. (1999). Leadership Quarterly & 31 & 8,4 \\
\hline $33^{\circ}$ & $\begin{array}{l}\text { Gardner, W. L., Avolio, B. J., Luthans, F., May, D. R., \& Walumbwa, F. O. (2005). } \\
\text { Leadership Quarterly }\end{array}$ & 30 & 8,2 \\
\hline $34^{\circ}$ & Blau, P. M. (1964). Exchange and Power in Social Life & 30 & 8,2 \\
\hline $35^{\circ}$ & Day, D. V. (2000). Leadership Quarterly & 29 & 7,9 \\
\hline $36^{\circ}$ & $\begin{array}{l}\text { Meindl, J. R., Ehrlich, S. B., \& Dukerich, J. M. (1985). Administrative Science } \\
\text { Quarterly }\end{array}$ & 29 & 7,9 \\
\hline $37^{\circ}$ & House, R. J. (1977). 1976 Theory Charismatic Leadership & 28 & 7,6 \\
\hline $38^{\circ}$ & Awamleh, R., \& Gardner, W. L. (1999). Leadership Quarterly & 28 & 7,6 \\
\hline $39^{\circ}$ & $\begin{array}{l}\text { Brown, M. E., Treviño, L. K., \& Harrison, D. A. (2005). Org. Behavior Human } \\
\text { Decision }\end{array}$ & 28 & 7,6 \\
\hline $40^{\circ}$ & Liden, R. C., \& Maslyn J. M. (1998). Journal of Management & 28 & 7,6 \\
\hline $41^{\circ}$ & Gardner, W. L., \& Avolio B. J. (1998). Acad. of Manag. Rev. & 28 & 7,6 \\
\hline $42^{\circ}$ & Dansereau, F., Graen, G., \& Haga, W. J. (1975). Organ. Behavior\& Human Perf. & 27 & 7,3 \\
\hline $43^{\circ}$ & Sy, T., Côté, S., \& Saavedra, R. (2005). Journal of Applied Psy. & 27 & 7,3 \\
\hline $44^{\circ}$ & Hunt, J. G., Boal, K. B., \& Dodge, G. E. (1999). Leadership Quarterly & 26 & 7,1 \\
\hline $45^{\circ}$ & Howell, J. M., \& Shamir, B. (2005). Acad. of Manag. Rev. & 26 & 7,1 \\
\hline $46^{\circ}$ & Liden, R. C., Sparrowe, R. T., \& Wayne, S. J. (1997). Research in personnel \& Human & 26 & 7,1 \\
\hline $47^{\circ}$ & Klein, K. J., Dansereau, F., \& Hall, R. J. (1994). Acad. of Manag. Rev. & 26 & 7,1 \\
\hline $48^{\circ}$ & Kozlowski, S. W. J., \& Klein, K. J. (2000). Multilevel Appro. & 25 & 6,8 \\
\hline $49^{\circ}$ & Kirkpatrick, S. A., \& Locke, E. A. (1996). Journal Applied Psy. & 25 & 6,8 \\
\hline $50^{\circ}$ & Hogg, M. A. (2001). Personality \& Social Psychology Rev. & 25 & 6,8 \\
\hline $51^{\circ}$ & George, J. M. (2000). Human Relations & 25 & 6,8 \\
\hline $52^{\circ}$ & $\begin{array}{l}\text { Avolio, B. J., Gardner, W. L., Walumbwa, F. O., Luthans, F., \& May, D. R. (2004). } \\
\text { Leadership Quarterly }\end{array}$ & 25 & 6,8 \\
\hline $53^{\circ}$ & Meindl, J. R. (1995). Leadership Quarterly & 25 & 6,8 \\
\hline $54^{\circ}$ & $\begin{array}{l}\text { Walumbwa, F. O., Avolio, B. J., Gardner, W. L., Wernsing, T. S., \& Peterson, S. J. } \\
\text { (2008). Journal of Management }\end{array}$ & 25 & 6,8 \\
\hline
\end{tabular}

Nota. Fonte: Elaborado pelos autores.

Por outro lado, as publicações mais frequentemente citadas são, em sua maioria, artigos de periódicos, sobretudo artigos publicados no próprio periódico analisado, que contribui com 14 destes 54 trabalhos (26\% dos mais citados). Nesse sentido, outro periódico com forte presença entre artigos mais citados foi o Journal of Applied Psychology, com oito artigos na tabela. Esta revista científica, apesar de ser voltada para a psicologia, é fonte de diversas publicações com alta visibilidade no campo e que constituem referências na construção das teorias e do corpo científico acerca da liderança na atualidade.

Cabe observar, ainda, os livros e capítulos de livros presentes entre as referências mais citadas, que somam 15 publicações. Além dos três primeiros, de Yukl (2006) e Bass (1990, 1985), aparece na nona posição o livro de Aiken e West (1991) - Multiple Regression: Testing and Interpreting Interactions. Como essa publicação é tida como um guia metodológico para, especificamente, pesquisas quantitativas, é possível inferir que há uma predominância de trabalhos empíricos publicados no período 
que utilizam métodos quantitativos. Além disso, foram contabilizadas 31.915 referências nos 368 artigos analisados, o que dá uma média de quase 87 citações $(\bar{x}=86,73)$. Essa informação demonstra o alto grau de aprofundamento e embasamento na literatura observado em artigos teóricos ou empíricos que lograram publicação no LQ. No quarto passo, penúltimo da análise, elaborou-se uma rede de cocitações (Figura 2) para os 30 artigos mais citados, utilizando como ferramenta o software desenvolvido por Borgatti, Everett e Freeman (2002): Ucinet. Com base na rede criada, é possível observar pares de artigos citados conjuntamente, identificando potenciais laços teóricos entre eles. Quanto mais ligações, maior a frequência de cocitações destes trabalhos na construção de um determinado corpo teórico. Na rede de cocitações (Figura 2), quanto mais afastados do centro, mais fracos são os laços, isto é, menor é a frequência de cocitações em outros trabalhos. Pode-se observar que o trabalho de Shamir et al. (1993) tem um papel central nesta rede, seguido, principalmente, pelo artigo de Dansereau et al. (1984), e Graen e Uhl-Bien (1995).

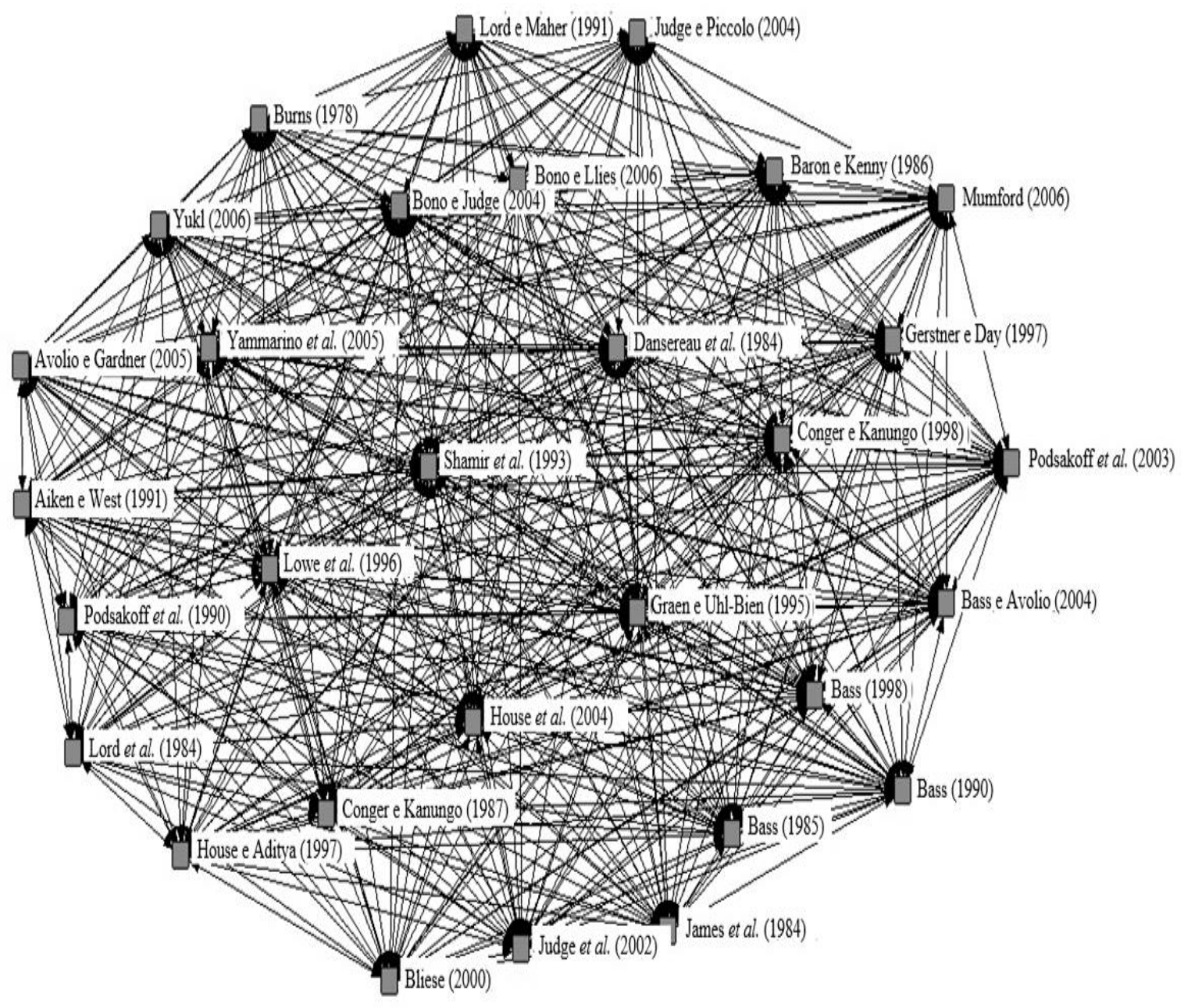

Figura 2. Rede de Cocitações

Fonte: Elaborado pelos autores.

Na última fase da análise, foi construído um mapa de cocitações para as 30 publicações mais citadas no período (Figura 3). O valor encontrado para o nível normalizado de stress do modelo foi considerado adequado $(0,968)$. A partir disso, foram identificados quatro clusters principais (agrupamentos de cocitações), que estão relacionados aos seguintes tópicos: Manuais e Ensaios Teóricos sobre Liderança (cluster 1), Teoria de Troca entre Líderes e Liderados (Leader-Member Exchange Theory [LMX]) (cluster 2), Teoria da Liderança Transformacional e Transacional (cluster 3) e Teoria da Liderança Carismática (cluster 4). 


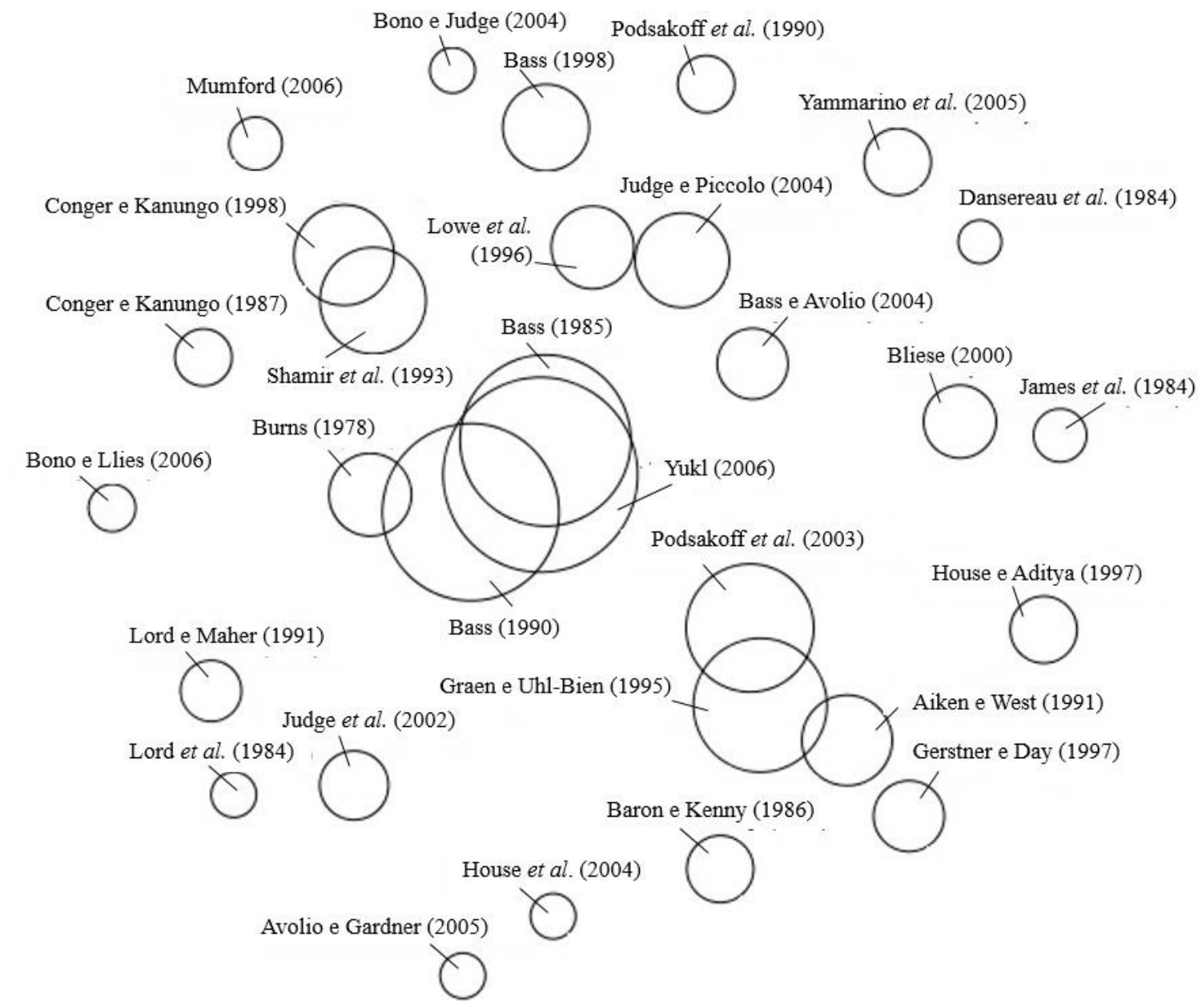

Figura 3. Mapa de Cocitações

Fonte: Elaborado pelos autores.

O cluster 1 reúne as obras que constituem pilares seminais do pensamento sobre o tema, com ênfase na nova liderança, ou fazem retrospectivas do estado da arte nessa área temática. As publicações nesse cluster oferecem as bases para os estudos sobre liderança. Os livros de Yukl (2006), Bass (1985, 1990) e Burns (1978) discutem diversas abordagens sobre o tema, assim como questões atemporais, muitas delas debatidas até os dias atuais. Este grupo detém o maior número de citações no conjunto estudado.

O cluster 2 compreende publicações que abordam a teoria LMX. Os trabalhos de Graen e UhlBien (1995) e Gerstner e Day (1997) parecem ser as principais peças na construção desse grupo. Algumas contribuições de Graen e Uhl-Bien (1995) são: a identificação de estágios de desenvolvimento do LMX, a elaboração de um modelo mais parcimonioso e prático para a teoria e, também, direcionamentos para futuros estudos que utilizem essa abordagem. O artigo de Gerstner e Day (1997) é uma meta-análise dos trabalhos que investigam a rede nomológica da teoria LMX, concluindo que os relacionamentos de mais alta qualidade e a ampliação do endogrupo (in group) de um líder estão positivamente associados com resultados organizacionais.

O terceiro cluster, que reúne o maior número de publicações que figuram entre as mais citadas no período, engloba pesquisas que exploram as teorias transformacional e transacional da liderança. Entre eles, o artigo de Podsakoff et al. (1990) investiga o impacto dos comportamentos de um líder transformacional nos comportamentos de cidadania organizacional de seus seguidores. $\mathrm{O}$ artigo de Bass (1998) explora a influência da moralidade do líder no contexto da liderança transformacional e conclui que não há espaço para líderes antiéticos nos pressupostos desta teoria. Os demais estudos, Lowe, 
Kroeck e Sivasubramaniam (1996), Judge e Piccolo (2004) e Bono e Judge (2004), constituem trabalhos quantitativos de revisão da literatura sobre essas perspectivas que aplicam o método de meta-análise. Nessas três últimas publicações, tanto a teoria transformacional quanto a transacional da liderança são analisadas em relação aos seus antecedentes e consequentes, com base nos estudos acumulados na literatura.

Por último, o cluster 4 concentra as publicações relacionadas à Teoria da Liderança Carismática. Dois trabalhos seminais dessa abordagem merecem maior destaque, os artigos de Conger e Kanungo (1987) e Shamir et al. (1993). O primeiro propõe um modelo que contempla a relevância do contexto organizacional no fenômeno da liderança carismática. Por sua vez, o estudo de Shamir et al. (1993) expande e aprofunda o arcabouço teórico dessa perspectiva, investigando o processo através do qual líderes carismáticos provocam transformações em seus seguidores.

Retomando o conjunto de perspectivas sobre a liderança descritas na revisão da literatura, os resultados dessa análise deixam claro que a Teoria das Trocas entre Líderes e Seguidores (LMX) e as novas teorias sobre a liderança, i.e., as teorias da Liderança Carismática e da Liderança Transacional/Transformacional constituem os corpos teóricos do campo nos quais se referenciam um número considerável de trabalhos publicados pelo LQ na contemporaneidade. Com base no mapa de cocitações, pode-se observar ainda a presença, embora pequena, de trabalhos com referência nas escolas centradas nos seguidores, particularmente as teorias implícitas sobre a liderança e a teoria de processamento de informações (Lord et al., 1984; Lord \& Maher, 1991), e em perspectivas contemporâneas associadas à escola dos traços (Judge, Bono, Ilies, \& Gerhardt, 2002).

Observa-se, também, a presença de um estudo seminal sobre a teoria da liderança autêntica no mapa de cocitações. O trabalho de Avolio e Gardner (2005) apresenta fundamentos conceituais sobre a autenticidade, articula os pressupostos básicos sobre a liderança autêntica, descreve os componentes e dimensões da teoria e analisa o desenvolvimento teórico dessa perspectiva até a data de sua publicação. Como a teoria da liderança autêntica começou a ser articulada no início deste século, sendo o espaço temporal decorrido desde então substancialmente menor comparativamente ao das demais teorias que alcançaram um grande número de citações, sua presença no mapa denota sua evidência no periódico.

Finalmente, vale notar os trabalhos de Bliese (2000) e James et al. (1984) próximos no mapa, e o de Podsakoff et al. (2003). Eles discorrem sobre a demonstração de concordância nas avaliações de líderes por seus subordinados em estudos empíricos quantitativos com grupos como unidades de análise, e sobre os vieses em análises estatísticas quando as variáveis são levantadas com base na mesma fonte e método de mensuração nas surveys, mais uma vez ressaltando a marcante presença de abordagens metodológicas de orientação positivista como base no desenvolvimento das pesquisas publicadas no LQ.

\section{Discussão}

Este artigo procurou analisar a produção de conhecimento contemporânea sobre a liderança, a partir de uma pesquisa bibliométrica feita com base nos artigos publicados nos últimos seis anos no The Leadership Quarterly, periódico temático com maior fator de impacto no meio acadêmico internacional. Os resultados da análise indicaram que, dos autores que mais publicaram no LQ nesse período, nove fazem parte do corpo editorial da revista. Cabe considerar, primeiramente, que só se chega ao cargo de editor de um periódico considerado o principal veículo internacional de difusão do pensamento e pesquisa sobre um tema após adquirir senioridade na carreira e fazer contribuições substantivas neste campo. Como esses pesquisadores permanecem ativamente envolvidos na vanguarda da produção de conhecimento e na formação de novos pesquisadores, sua marcante participação como autores parece ser uma decorrência natural. 
Porém, apesar da inconteste senioridade, expertise e qualidade da produção científica desses autores-editores, sua destacada contribuição para a produção do periódico também sugere a precedência das abordagens e perspectivas que esposam nessa publicação, uma tendência relativamente comum nas comunidades científicas, e há muito discutida pelos estudiosos da teoria da ciência (e.g.: Kuhn, 2003). As observações da análise realizada permitem afirmar que os artigos que lograram publicação na revista nos últimos anos tendem a se orientar por perspectivas teóricas que refletem o pensamento tradicional norte-americano sobre o tema, e que aplicam desenhos de pesquisa e ferramentas de análise quantitativas - tendência verificada também em análises passadas (Lowe \& Gardner, 2000). Isso sugere que a produção do periódico está mais alinhada com o modelo tipicamente positivista de produção do conhecimento. Possivelmente esta tendência tenha levado pesquisadores interessados em ampliar a diversidade de métodos no campo a fundar outro periódico, o Leadership (Collinson \& Grint, 2005), cujo viés editorial parece favorecer mais artigos pautados em perspectivas interpretativas, discursivas e fenomenológicas (Bryman et al., 2011), em linha com a proposta de seus fundadores.

Apesar de $60 \%$ dos trabalhos publicados no LQ terem como primeiro autor pesquisadores de universidades norte-americanas, a análise também verificou que a colocação de artigos na revista por autores de outras partes do mundo cresceu em relação ao percentual observado no passado no campo da liderança (House \& Adytia, 1997). Isso sugere que o conhecimento difundido pelo periódico vem progressivamente ampliando seu escopo em termos de fronteiras geográficas, o que favorece a construção de um campo de conhecimento sobre a liderança de fato internacional. Porém, pode-se especular que essa inserção seja facilitada quando as perspectivas teóricas investigadas por autores estrangeiros e o tratamento metodológico aplicado em suas pesquisas guardam uma maior proximidade dos modelos que predominam na revista.

Um dos objetivos basilares do estudo era observar como as principais pesquisas científicas sobre liderança estão configuradas atualmente na comunidade acadêmica internacional e seus veículos de difusão do conhecimento. Nesse sentido, os resultados representam um bom diagnóstico das tendências verificadas no periódico selecionado. Com base nesses achados, pesquisadores terão uma orientação e um alicerce a mais na elaboração de futuros estudos e em suas decisões sobre seu encaminhamento para publicação. Constatou-se a predominância de estudos embasados nas teorias da nova liderança, ponto também ressaltado por Gardner et al. (2010) em sua discussão sobre a produção do LQ de 2000 a 2009. Poucos estudos no acervo contemporâneo do LQ citam as teorias clássicas, como as abordagens do traço e as situacionais. Observou-se, ainda, o alto nível de embasamento teórico na fundamentação de estudos que lograram publicação no periódico, haja vista o grande número de citações incluídas em cada trabalho publicado.

Vale ressaltar, ainda, as observações de Antonakis, Bastardoz e Schriesheim (2014) sobre os fatores que fazem com que artigos sobre liderança sejam altamente citados na literatura na atualidade: o uso de métodos como equações estruturais e meta-análise, e o enfoque nas teorias carismática e transformacional. O rigor teórico, mas, sobretudo, metodológico, é uma tendência observada no cenário internacional não somente para os estudos sobre a liderança, mas para a área de comportamento organizacional como um todo (Sobral \& Mansur, 2013). As observações de Sobral e Mansur, ao analisar a produção científica brasileira no campo frente às tendências internacionais, além de destacarem a escassez de estudos sobre grupos e sobre a própria liderança, verificam o predomínio de abordagens qualitativas e de técnicas de análise pouco robustas na produção nacional, o que pode explicar, pelo menos em parte, a escassez de trabalhos realizados por autores de centros de pesquisa brasileiros no LQ.

Uma das possíveis razões para a predominância do paradigma positivista e dos métodos quantitativos no LQ seria a maior facilidade de consenso sobre sua forma ideal de aplicação, tendo em vista sua natureza objetiva. Porém, fica claro que outras perspectivas que enfatizam a subjetividade e a construção social do fenômeno aparecem com menor frequência neste periódico. No entanto, tais perspectivas podem se tornar atraentes uma vez que, na modernidade, novas mídias têm afetado as interações sociais e o comportamento humano. Neste contexto, tais abordagens poderiam dotar o campo de estudos sobre a liderança de um maior pluralismo investigativo, com aplicação de perspectivas interpretativas, discursivas, críticas e fenomenológicas, oferecendo oportunidades de expansão. 


\section{Conclusão}

O presente artigo contribui especificamente para a identificação dos principais corpos teóricos que orientam os estudos sobre liderança no periódico internacional que é hoje considerado a principal referência na produção de conhecimento neste campo: o The Leadership Quarterly. Assim, este trabalho apresenta importantes subsídios para ampliar a produção do conhecimento sobre o tema, bem como para informar a difusão do conhecimento acumulado sobre a liderança nos círculos acadêmicos de formação no Brasil. Além da apresentação da pesquisa de ponta sobre liderança encontrada em um de seus principais veículos de divulgação, este artigo também identifica os trabalhos que têm embasado essa produção científica, e que devem ser considerados na seleção de leituras essenciais para o acompanhamento desse campo do conhecimento por acadêmicos e profissionais do mercado interessados no tema e em participar como autores no cenário internacional. Assim, ele também pode contribuir para reduzir a lacuna ainda existente na participação de pesquisadores latino-americanos em geral, e brasileiros especificamente, na construção do pensamento contemporâneo internacional sobre a liderança (c.f. Sant'anna et al., 2009), e para estimular seu maior engajamento no cenário global da produção do conhecimento sobre o tema, bem como a expansão e amadurecimento dos estudos no Brasil (Fonseca et al., 2015).

A decisão por conduzir esta pesquisa com foco nos últimos seis anos teve a intenção de identificar as tendências mais atuais nesse periódico. Por outro lado, os resultados desta bibliometria se restringem somente à literatura produzida nesse período. A análise da produção publicada num período mais amplo pode expandir este trabalho no futuro, e permitir uma melhor visão histórica das dinâmicas e tendências do campo. Além disso, a produção de pesquisa internacional sobre liderança também é veiculada em outros periódicos, como o Journal of Applied Psychology e o Academy of Management Journal. Tendo em vista seu escopo mais generalista, o volume de produção sobre liderança nesses periódicos é consideravelmente menor do que o volume em um periódico temático e especializado como o The Leadership Quarterly (Dinh et al., 2014), e que por isso exerce uma grande influência no desenvolvimento de teorias e entendimento do fenômeno. Não obstante, estudos futuros podem ampliar este trabalho, analisando a produção de pesquisa sobre liderança publicada em periódicos generalistas no mesmo período ou em períodos expandidos, bem como em outros periódicos temáticos dedicados ao estudo da liderança, aplicando um enfoque comparativo.

A globalização de mercados e a expansão de negócios internacionais têm aumentado o interesse por pesquisas que considerem o impacto do contexto sobre a liderança (e.g., House, Hanges, Javidan, Dorfmann, \& Gupta, 2004). Apesar da observação de que houve, nos últimos anos, uma maior participação de autores estrangeiros no LQ, há ainda um forte viés norte-americano nas teorias, modelos e métricas que prevalecem em sua produção. Assim, permanece a necessidade de um melhor entendimento sobre o exercício da influência, característico da liderança, em diferentes culturas. Particularmente em países em desenvolvimento, que compartilham algumas características, como o colonialismo histórico, desigualdades econômicas e sistemas legais ineficientes, muitas são as oportunidades para discutir as premissas teóricas vigentes e relativizá-las vis-à-vis as especificidades da cultura local. Assim, as possibilidades para a pesquisa sobre a liderança no contexto brasileiro são muitas, e a relevância de seus achados, tanto do ponto de vista teórico quanto prático, colocam-nas no radar das principais publicações internacionais.

Por fim, vale ressaltar o alto rigor e critério metodológico que caracteriza as publicações sobre o tema nesse periódico, ponto importante para pesquisadores que intencionam submeter artigos para publicação no The Leadership Quarterly. Do ponto de vista do método, os trabalhos sobre liderança com base em análises robustas tendem a ser priorizados, sobretudo aqueles de natureza quantitativa. Parece importante, também, notar que as teorias da nova liderança parecem gozar de maior destaque nessa publicação. Assim, estudos que visem ampliar o conhecimento sobre essas teorias em escopo e validade, que relativizem sua universalidade, ou que as relacionem com outras teorias podem também despertar o interesse de seu corpo editorial. Tendo em vista a expansão da participação de autores de diferentes nacionalidades na revista nos últimos anos, o momento atual parece profícuo para a inserção 
de pesquisas brasileiras no periódico e, assim, ampliar a representação da produção científica nacional neste importante campo do conhecimento.

\section{Referências}

Aiken, L. S., \& West, S. G. (1991). Multiple regression: testing and interpreting interactions. Newbury Park, CA: Sage.

Antonakis, J., Bastardoz, N., Liu, Y., \& Schriesheim, C. A. (2014). What makes articles highly cited?. The Leadership Quarterly, 25(1), 152-179. doi: 10.1016/j.leaqua.2013.10.014

Avolio, B. J., \& Gardner, W. L. (2005). Authentic leadership development: getting to the root of positive forms of leadership. The Leadership Quarterly, 16(3), 315-338. doi: 10.1016/j.leaqua.2005.03.001

Avolio, B. J., Gardner, W. L., Walumbwa, F. O., Luthans, F., \& May, D. R. (2004). Unlocking the mask: a look at the process by which authentic leaders impact follower attitudes and behaviors. The Leadership Quarterly, 15(6), 801-823. doi: 10.1016/j.leaqua.2004.09.003

Awamleh, R., \& Gardner, W. L. (1999). Perceptions of leader charisma and effectiveness: the effects of vision content, delivery, and organizational performance. The Leadership Quarterly, 10(3), 345373. doi: 10.1016/S1048-9843(99)00022-3

Baron, R. M., \& Kenny, D. A. (1986). The moderator-mediator variable distinction in social psychological research: conceptual, strategic, and statistical considerations. Journal of Personality and Social Psychology, 51(6), 1173-1182. doi: 10.1037/0022-3514.51.6.1173

Bass, B. M. (1985). Leadership and performance beyond expectations. New York: Free Press.

Bass, B. M. (1990). Bass and stogdill's handbook of leadership: theory, research, and managerial applications (3rd ed.). New York: Free Press.

Bass, B. M. (1998). Transformational leadership: industry, military, and educational impact. Mahwah, NJ: Lawrence Erlbaum.

Bass, B. M. (2008). The Bass handbook of leadership: theory, research, and managerial applications (4th ed.). New York: Free Press.

Bass, B. M., \& Avolio, B. J. (2004). Multifactor leadership questionnaire: manual leader form, rater, and scoring key for MLQ (Form 5x-Short). Redwood City, CA: Mind Garden.

Bass, B. M., \& Steidlmeier, P. (1999). Ethics, character, and authentic transformational leadership behavior. The Leadership Quarterly, 10(2), 181-217. doi: 10.1016/S1048-9843(99)00016-8

Blau, P. M. (1964). Exchange and power in social life. New York: Academic.

Bliese, P. D. (2000). Within-group agreement, non-independence, and reliability: implications for data aggregation and analysis. In K. J. Klein \& S. W. J. Kozlowski (Eds.), Multilevel theory, research and methods in organizations: foundations, extensions, and new directions (pp. 349-381). San Francisco, CA: Jossey-Bass.

Bono, J. E., \& Illies, R. (2006). Charisma, positive emotions and mood contagion. The Leadership Quarterly, 17(4), 317-334. doi: 10.1016/j.leaqua.2006.04.008

Bono, J. E., \& Judge, T. A. (2004). Personality and transformational and transactional leadership: a meta-analysis. Journal of Applied Psychology, 89(5), 901-910. doi: 10.1037/0021-9010.89.5.901 
Borgatti, S. P., Everett, M. G., \& Freeman, L. C. (2002). Ucinet 6 for Windows: software for social network analysis. Harvard, MA: Analytic Technologies.

Bowditch, J. L., \& Buono, A. F. (2002). Elementos do comportamento organizacional. São Paulo: Pioneira.

Brown, M. E., Treviño, L. K., \& Harrison, D. A. (2005). Ethical leadership: a social learning perspective for construct development and testing. Organizational Behavior and Human Decision Processes, 97(2), 117-134. doi: 10.1016/j.obhdp.2005.03.002

Bryman, A. (2004). Liderança nas organizações. In S. R. Clegg, C. Hardy, \& W. R. Nord (Orgs.), Handbook de estudos organizacionais (Cap. 10, pp. 257-281). São Paulo: Atlas.

Bryman, A., Collinson, D., Grint, K., Jackson, B., \& Uhl-Bien, M. (Eds). (2011). The sage handbook of leadership. Thousand Oaks, CA: Sage Publications.

Burns, J. M. (1978). Leadership. New York: Harper \& Row Publishers.

Calder, B. J. (1977). An attribution theory of leadership. In B. M. Staw \& G. R. Salancik (Eds.), New directions in organizational behavior (pp. 179-204). Chicago: St. Clair.

Collinson, D., \& Grint, K (2005). Editorial: the leadership agenda. Leadership, 1(1), 5-9. doi: $10.1177 / 1742715005049346$

Conger, J. A., \& Kanungo, R. N. (1987). Toward a behavioral theory of charismatic leadership in organizational settings. Academy of Management Review, 12(4), 637-647. doi: 10.5465/AMR.1987.4306715

Conger, J. A., \& Kanungo, R. N. (1998). Charismatic leadership in organizations. Thousand Oaks, CA: Sage Publications.

Cooper, C. D., Scandura, T. A., \& Schriesheim, C. A. (2005). Looking forward but learning from our past: potential challenges to developing authentic leadership theory and authentic leaders. The Leadership Quarterly, 16(3), 475-493. doi: 10.1016/j.leaqua.2005.03.008

Dansereau, F., Alutto, J. A., \& Yammarino, F. J. (1984). Theory testing in organizational behavior: the variant approach. Englewood Cliffs, NJ: Prentice-Hall.

Dansereau, F., Graen, G., \& Haga, W. J. (1975). A vertical dyad linkage approach to leadership within formal organizations: a longitudinal investigation of the whole making process. Organizational Behavior and Human Performance, 13(1), 46-78. doi: 10.1016/0030-5073(75)90005-7

Day, D. V. (2000). Leadership development: a review in context. The Leadership Quarterly, 11(4), 581613. doi: 10.1016/S1048-9843(00)00061-8

Day, D. V., \& Antonakis, J. (2012). The nature of leadership (2nd ed.). Thousand Oaks, CA: SAGE Publications, Inc.

Delfino, I. A. L., Silva, A. B., \& Rohde, L. R. (2010, setembro). A produção acadêmica sobre liderança no Brasil: uma análise bibliométrica dos artigos publicados em eventos e periódicos entre 1995 e 2009. Anais do Encontro Nacional da Associação Nacional de Pós-Graduação e Pesquisa em Administração, Rio de Janeiro, RJ, Brasil, 34.

Dinh, J. E., Lord, R., Gardner, W. L., Meuserd, J. D., Liden, R., \& Huc, J. (2014). Leadership theory and research in the new millennium: current theoretical trends and changing perspectives. The Leadership Quarterly, 25(1), 36-62. doi: 10.1016/j.leaqua.2013.11.005 
Eden, D., \& Leviathan, U. (1975). Implicit leadership theory as a determinant of the factor structure underlying supervisory behavior scales. Journal of Applied Psychology, 60(6), 736-741. doi: 10.1037/0021-9010.60.6.736

Elsevier. (n.d.). The leadership quarterly editorial board. Retrieved January 26, 2014, from http://www.journals.elsevier.com/the-leadership-quarterly/editorial-board

Fernandes, M. E. R., \& Vaz, S. L. (2010). Tendências contemporâneas no estudo da liderança: uma análise em artigos publicados no Academy of Management Journal. In R. E. Nelson \& A. S. Sant'Anna (Eds.), Liderança: entre a tradição, a modernidade e a pós-modernidade (pp. 147169). Rio de Janeiro: Elsevier Editora.

Fiedler, F. E. (1967). A theory of leadership effectiveness. New York: McGraw-Hill.

Fonseca, A. M., Porto, J. B., \& Borges-Andrade, J. E. (2015). Liderança: um retrato da produção científica brasileira. Revista de Administração Contemporânea, 19(3), 290-310. Recuperado de http://www.scielo.br/pdf/rac/v19n3/1415-6555-rac-19-03-00290.pdf. doi: 10.1590/19827849rac20151404

Gardner, W. L., \& Avolio, B. J. (1998). The charismatic relationship: a dramaturgical perspective. Academy of Management Review, 23(1), 32-58. doi: 10.5465/AMR.1998.192958

Gardner, W. L., Avolio, B. J., Luthans, F., May, D. R., \& Walumbwa, F. O. (2005). "Can you see the real me?" A self-based model of authentic leader and follower development. The Leadership Quarterly, 16(3), 343-372. doi: 10.1016/j.leaqua.2005.03.003

Gardner, W. L., Lowe, K. B., Moss, T. W., Mahoney, K. T., \& Cogliser, C. C. (2010). Scholarly leadership of the study of leadership: a review of The Leadership Quarterly's second decade, 2000-2009. The Leadership Quarterly, 21(6), 922-958. doi: 10.1016/j.leaqua.2010.10.003

George, J. M. (2000). Emotions and leadership: the role of emotional intelligence. Human Relations, 53(8), 1027-1055. doi: 10.1177/0018726700538001

Gerstner, C. R., \& Day, D. V. (1997). Meta-analytic review of leader-member exchange theory: correlates and construct issues. Journal of Applied Psychology, 82(6), 827-844. doi: $10.1037 / / 0021-9010.82 .6 .827$

Graen, G. B., \& Uhl-bien, M. (1995). Relationship-based approach to leadership: development of leadermember exchange (LMX) theory over 25 years: apllying a multi-level multi-domain perspective. The Leadership Quarterly, 6(2), 219-247. doi: 10.1016/1048-9843(95)90036-5

Grint, K. (2011). A history of leadership. In A. Bryman, D. Collinson, K. Grint, B. Jackson, \& M. UhlBien (Eds.), The sage handbook of leadership (pp. 3-14). Thousand Oaks, CA: Sage Publications.

Hogg, M. A. (2001). A social identity theory of leadership. Personality and Social Psychology Review, 5(3), 184-200. doi: 10.1207/S15327957PSPR0503_1

House, R. J. (1977). A 1976 theory of charismatic leadership. In J. G. Hunt \& L. L. Larson (Eds.), Leadership: the cutting edge (pp. 189-207). Carbondale: Southern Illinois University Press.

House, R. J., \& Aditya, R. N. (1997). The social scientific study of leadership: Quo vadis? Journal of Management, 23(3), 409-473. doi: 10.1177/014920639702300306

House, R. J., Hanges, P. J., Javidan, M., Dorfmann, P. W., \& Gupta, V. (Eds.). (2004). Culture, leadership, and organizations: the GLOBE study of 62 societies. Thousand Oaks, CA: Sage. 
Howell, J. M., \& Shamir, B. (2005). The role of followers in the charismatic leadership process: relationships and their consequences. Academy of Management Review, 30(1), 96-112. doi: 10.5465/AMR.2005.15281435

Hunt, J. G., Boal, K. B., \& Dodge, G. E. (1999). The effects of visionary and crisis-responsive charisma on followers: an experimental examination of two kinds of charismatic leadership. The Leadership Quarterly, 10(3), 423-448. doi: 10.1016/S1048-9843(99)00027-2

James, L. R., Demaree, R. G., \& Wolf, G. (1984). Estimating within-group interrater reliability with and without response bias. Journal of Applied Psychology, 69(1), 85-98. doi: 10.1037/00219010.69.1.85

Judge, T. A., Bono, J. E., Ilies, R., \& Gerhardt, M. (2002). Personality and leadership: a qualitative and quantitative review. The Journal of Applied Psychology, 87(4), 765-780. doi: 10.1037//00219010.87.4.765

Judge, T. A., \& Piccolo, R. F. (2004). Transformational and transactional leadership: a meta-analytic test of their relative validity. Journal of Applied Psychology, 89(5), 755-768. doi: 10.1037/00219010.89.5.755

Kirkpatrick, S. A., \& Locke, E. A. (1996). Direct and indirect effects of three core charismatic leadership components on performance and attitudes. Journal of Applied Psychology, 81(1), 36-51. doi: 10.1037/0021-9010.81.1.36

Klein, K. J., Dansereau, F., \& Hall, R. J. (1994). Levels issues in theory development, data collection and analysis. Academy of Management Review, 19(2), 195-229. doi: 10.5465/AMR.1994.9410210745

Kotter, J. P. (2001). What leaders really do. Harvard Business Review, 79(11), 85-96. doi: 10.1109/EMR.2009.5235494

Kozlowski, S. W. J., \& Klein, K. J. (2000). A multilevel approach to theory and research in organizations: contextual, temporal, and emerging processes. In K. J. Klein \& S. W. J. Kozlowski (Eds.), Multilevel theory, research and methods in organizations: foundations, extensions, and new directions (pp. 3-90). San Francisco: Jossey-Bass.

Kuhn, T. (2003). A estrutura das revoluções científicas (7a ed.). São Paulo: Perspectiva.

Liden, R. C., \& Maslyn, J. M. (1998). Multidimensionality of leader-member exchange: an empirical assessment through scale development. Journal of Management, 24(1), 43-72. doi: 10.1016/S0149-2063(99)80053-1

Liden, R. C., Sparrowe, R. T., \& Wayne, S. J. (1997). Leader-member exchange theory: the past and potencial for the future. In G. Ferris (Ed.), Research in personnel and human resource management (pp. 47-119). Greenwich, CT: JAI Press.

Lord, R. G., Binning, J. F., Rush, M. C., \& Thomas J. C. (1978). The effect of performance cues and leader behavior on questionnaire ratings of leadership behavior. Organizational Behavior and Human Performance, 21(1), 27-39. doi: 10.1016/0030-5073(78)90036-3

Lord, R. G., Foti, R. J., \& De Vader, C. L. (1984). A test of leadership categorization theory: internal structure, information processing, and leadership perceptions. Organizational Behavior and Human Performance, 34(3), 343-378. doi: 10.1016/0030-5073(84)90043-6

Lord, R. G., \& Maher, K. J. (1991). Leadership and information processing: linking perceptions and performance. Boston, MA: Unwin Hyman. 
Lowe, K. B., \& Gardner, W. L. (2000). A decade of The Leadership Quarterly: contributions and challenges for the future. The Leadership Quarterly, 11(4), 459-514.

Lowe, K. B., \& Gardner, W. L. (2001). Ten years of the leadership quarterly: contributions and challenges for the future. The Leadership Quarterly, 11(4), 459-514. doi: 10.1016/S10489843(00)00059-X

Lowe, K. B., Kroeck, K. G., \& Sivasubramaniam, N. (1996). Effectiveness correlates of transformational and transactional leadership: a meta-analytic review of the MLQ literature. The Leadership Quarterly, 7(3), 385-425.

Luthans, F., \& Avolio, B. J. (2003). Authentic leadership: a positive developmental approach. In K. S. Cameron, J. E. Dutton, \& R. E. Quinn (Eds.), Positive organizational scholarship (pp. 241-261). San Francisco: Barrett-Koehler.

Manz, C. C., \& Sims, H. P., Jr. (1991). Superleadership: beyond the myth of heroic leadership. Organizational Dynamics, 19(4), 18-35. doi: 10.1016/0090-2616(91)90051-A

Meindl, J. R. (1995). The romance of leadership as a follower-centric theory: a social constructionist approach. The Leadership Quarterly, 6(3), 329-341. doi: 10.1016/1048-9843(95)90012-8

Meindl, J. R., Ehrlich, S. B., \& Dukerich, J. M. (1985). The romance of leadership. Administrative Science Quarterly, 30(1), 78-102. doi: 10.2307/2392813

Mumford, M. D. (2006). Pathways to outstanding leadership: a comparative analysis of charismatic, ideological, and pragmatic leaders. New Jersey: Lawrence Erlbaum Associates.

Northouse, P. G. (2010). Leadership theory and practice. SAGE Publications.

Parry, K. W., \& Bryman, A. (2006). Leadership in organizations. In S. Clegg, C. Hardy, T. Lawrence, \& W. Nord (Eds.), Sage handbook of organization studies (pp. 447-468). Thousand Oaks, CA: Sage Publications.

Pearce, C. L., \& Sims, H. P. (2001). Shared leadership: toward a multi-level theory of leadership. Advances in Interdisciplinary Studies of Work Teams, 7, 115-139. doi: 10.1016/S15720977(00)07008-4

Pfeffer, J. (1977). The ambiguity of leadership. Academy of Management Review, 2(1), 104-112. doi: $10.2307 / 257611$

Podsakoff, P. M., Mackenzie, S. B., Moorman, R. H., \& Fetter, R. (1990).Transformational leader behaviors and their effects on followers' trust in leader, satisfaction, and organizational citizenship behaviors. The Leadership Quarterly, 1(2), 107-142. doi: 10.1016/10489843(90)90009-7

Podsakoff, P. M., Mackenzie, S. C., Podsakoff, N. P., \& Lee, J.-Y. (2003). Common method biases in behavioral research: a critical review of the literature and recommended remedies. Journal of Applied Psychology, 88(5), 879-903. doi: 10.1037/0021-9010.88.5.879

Sant'anna, A. S., Vaz, S. L., Nelson, R. E., Campos, M. S., \& Leonel, J. N. (2009, setembro). Liderança: uma análise sob a perspectiva de acadêmicos brasileiros e norte-americanos. Anais do Encontro Nacional da Associação Nacional de Pós-Graduação e Pesquisa em Administração, São Paulo, SP, Brasil, 33.

Schein, E. (2007). Cultura organizacional e liderança. São Paulo, SP: Atlas. 
Schreyer, E. (2010, agosto 3). Why leadership matters. Forbes. Retrieved from http://www.forbes.com/2010/03/08/leader-business-visionary-forbes-woman-leadershipjob.html

Serra, F. R., Ferreira, M. P., Almeida, M. I. R., \& Vanz, S. A. S. (2012). A pesquisa em administração estratégica nos primeiros anos do século XXI: um estudo bibliométrico de citação e cocitação no Strategic Management Journal entre 2001 e 2007. Estratégia e Negócios, 5(2), 257-274.

Shamir, B., House, R. J., \& Arthur, M. B. (1993). The motivational effect of charismatic leadership: a self-concept based theory. Organization Science, 4(4), 577-594. doi: 10.1287/orsc.4.4.577

Sobral, F. J. B. A., \& Mansur, J. A. (2013). Produção científica brasileira em comportamento organizacional no período 2000-2010. Revista de Administração de Empresas, 53(1), 21-34. doi: $10.1590 / \mathrm{S} 0034-75902013000100003$

Sy, T., Côté, S., \& Saavedra, R. (2005). The contagious leader: impact of the leader's mood on the mood of group members, group affective tone, and group processes. Journal of Applied Psychology, 90(2), 295-305. doi: 10.1037/0021-9010.90.2.295

Vieira, A. C. G., \& Fischer, A. L. (2005). Análise da produção científica em clima, cultura e remuneração e salários entre 1990-2004. Anais do Seminários em Administração (SEMEAD), São Paulo, SP, Brasil, 8.

Walumbwa, F. O., Avolio, B. J., Gardner, W. L., Wernsing, T. S., \& Peterson, S. J. (2008). Authentic leadership: development and validation of a theory-based measure. Journal of Management, 34(1), 89-126. doi: 10.1177/0149206307308913

Weber, M. (1947). The theory of social and economic organization (A. Henderson \& T. Parsons, Trans.). New York, N.Y: The Free Press. (Original work published 1920)

White, D., \& Mccain, K. (1998). Visualizing a discipline: an author co-citation analysis of information science, 1972-1995. Journal of the American Society for Information Science, 49(4), 327-355. doi: 10.1002/(SICI)1097-4571(19980401)49:4<327::AID-ASI4>3.0.CO;2-4

White, H., \& Griffith, B. (1981). Author co-citation: a literature measure of intellectual structure. Journal of the American Society for Information Science, 32(3), 163-171. doi: 10.1002/asi.4630320302

Yammarino, F., Dionne, S. D., Chun, J. A., \& Dansereau, F. (2005). Leadership and levels of analysis: a state-of-the-science review. The Leadership Quarterly, 16(6), 879-919. doi: 10.1016/j.leaqua.2005.09.002

Yammarino, F., Dionne, S., Schriesheim, C., \& Dansereau, F. (2008). Authentic leadership and positive organizational behavior: a meso, multi-level perspective. The Leadership Quarterly, 19(6), 693707. doi: 10.1016/j.leaqua.2008.09.004

Yukl, G. (1989). Managerial leadership: a review of theory and research. Journal of Management, 15(2), 251-289. doi: 10.1177/014920638901500207

Yukl, G. (1999). An evaluation of conceptual weaknesses in transformational and charismatic leadership theories. The Leadership Quarterly, 10(2), 285-205. doi: 10.1016/S1048-9843(99)00013-2

Yukl, G. (2006). Leadership in organizations. Upper Saddle River, NJ: Prentice-Hall.

Yukl, G. (2012). Effective leadership behavior: what we know and what questions need more attention. Academy of Management Perspectives, 26(4), 66-85. doi: 10.5465/amp.2012.0088 


\section{Dados dos Autores}

Lucas Martins Turano

Rua Marquês de São Vicente, 225, Gávea, 22451-900, Rio de Janeiro, RJ, Brasil. E-mail: lucas.turano2@ gmail.com

Flávia Cavazotte

Rua Marquês de São Vicente, 225, Gávea, 22451-900, Rio de Janeiro, RJ, Brasil. E-mail: flavia.cavazotte@ iag.puc-rio.br 